\title{
MEASUREMENTS RELATED TO PAIN IN NEUROCIRCULATORY ASTHENIA, ANXIETY NEUROSIS, OR EFFORT SYNDROME: LEVELS OF HEAT STIMULUS PERCEIVED AS PAINFUL AND PRODUCING WINCE AND WITHDRAWAL REACTIONS ${ }^{1}$
}

\author{
By WILLIAM P. CHAPMAN, MANDEL E. COHEN, AND STANLEY COBB \\ (From the Department of Medicine, Massachusetts General Hospital, the Massachusetts General \\ Hospital Branch of the Hall-Mercer Hospital, the Department of Medicine and \\ Neurology and Psychiatry of the Harvard Medical School, Boston)
}

(Received for publication August 4, 1946)

Multiple complaints of discomfort such as aches, pains and distress are a common finding in patients with neurocirculatory asthenia (N.C.A.). Among the symptoms listed in our patients with this condition are chest pain 92 per cent, headaches 66 per cent, "indigestion" 64 per cent, marked selfobservation including observation of disagreeable symptoms 64 per cent. In addition, discomfort seems to affect the behavior and lead to great disability in these patients. In attempting to put through a program of training, it was found that patients would not submit to the various exercises proposed by the trainer (1). The patients stated that exercise made them too uncomfortable and led to aches and pains.

It was felt, therefore, that investigation of the patients' level of awareness of painful stimuli, i.e. perception, and the patients' reaction to painful stimuli, should be studied. For the purpose of studying the threshold at which patients perceived a standard stimulus as painful, and the level at which the patient reacted (winced or pulled away), we employed the Hardy-Wolff radiation apparatus (2).

\section{METHOD}

On grounds of history alone, 2 groups of patients were distinguished. Those who had a life long course, or who could never do hard work or take part in athletics, were called chronic N.C.A.; those who gave convincing evidence of good health, good work or athletic ability and nervous stability previous to onset of the disorder were called acute N.C.A. Measurements were made in 94 patients, members of the armed forces, of whom 63 were cases of chronic N.C.A., and 31 cases of acute N.C.A.

.1 The work described in this paper was done under a contract, recommended by the Committee on Medical Research, between the Office of Scientific Research and Development and the Massachusetts General Hospital. Responsible Investigators: Stanley Cobb and Paul D. White.
The control subjects were 44 healthy individuals, 36 of whom were in military service, and 8 medical students. Patients and controls were men, and were roughly comparable as regards age range, economic, social and ethnic groups. Additional control subjects were 17 convalescent soldiers recovering from infected bone injuries sustained in combat or while in military service.

The stimulus consisted of varying intensities of heat supplied by the radiation apparaus (3). The source of heat was a 1,000 watt Mazda lamp with the light focused onto the midline of the forehead by 2 plano-convex lenses through an aperture $2.5 \mathrm{~cm}^{2}$ in area. To standardize the absorption of light, the forehead was first blackened with India ink. Each exposure was kept constant at 3 seconds by means of a shutter operated by a telechron motor, and the intensity was varied uniformly by a wire rheostat. The amount of stimulus used was calibrated periodically by a radiometer, and expressed in absolute end point values of gram cal. per sec. and $\mathrm{cm}^{2}$ of skin surface.*

Each subject was tested on 2 separate occasions, but never on the same day. With few exceptions, each test consisted of from 10 to 14 exposures to the stimulus, with approximately a 2 -minute interval between exposures. Before the start of the first test, no comments were made or instructions given, other than to tell the subject to keep his eyes closed during each stimulus. After each exposure the subject was asked these non-committal questions : (1) "What did you feel?" (2) "How would you describe what you felt when the stimulus was most intense?" (3) "Was the stimulus as intense, less or more intense than the previous one?" (4) "Was the stimulus like anything you have ever felt before?" (A card with 7 numbered circles varying from the diameter of a silver dollar, $4 \mathrm{~cm}$., to a pin head, $1 \mathrm{~mm}$., was held before the subject.) $\mathrm{He}$ was asked which circle corresponded in area to the size of the place on his forehead where the stimulus seemed most intense. The purpose of these questions was to have the patient describe what he felt when the stimulus was applied, avoiding suggesting the answer.

We also wished to learn whether N.C.A. subjects described their feelings at the painful level in the same or in a different manner from the control subjects.

The second test was administered in a slightly different

* This is commonly expressed as $\mathrm{gm}$. cal./sec./cm. 
manner from the first. The subject was given the following description of the stimulus: "At the beginning, the exposures feel like a warm glow. As they become more intense, the sensation feels smaller and hot or burny. Eventually, the most intense part of the stimulus changes from a burn to a sharp piercing quality about the size of a pencil point." $\mathrm{He}$ was also asked to keep his forehead at the aperture until told to move it away.

The lowest level of stimulus at which the subject said he felt a sharp jabbing or piercing sensation, i.e., the endpoint for perception, was calculated as the mean of the consistent values plus the inconsistent values. A consistent value was one at which the subject felt the sharp, jabbing or piercing sensation, but it must be one of a series on a given day in which there were no failures at perceiving the endpoint sensation. An inconsistent value was one at which the subject felt the endpoint sensation at least once but also failed to do so on one or more subsequent exposures at that level. Any values which were higher than the consistent ones were excluded. The threshold of motor reaction was taken to be the lowest level at which the subject winced, as evidenced by a beginning contraction of the muscles at the outer canthus of the eye. This value was calculated in the same manner as that for the subjective endpoint of pain, that is, by taking the mean of the consistent value plus the inconsistent value.

From the first exposure where a warm glow was felt, to levels where the sharp jabbing endpoint was felt, and where wincing occurred, the stimulus was varied from .030 to $.040 \mathrm{gram}$ cal. per sec. and $\mathrm{cm}^{2}$ each time. In order to obtain as closely as possible the endpoint levels, the stimulus was altered as little as .005 or .010 gram cal. per sec. and $\mathrm{cm}^{2}$ each time. At the completion of each test, notations were made regarding factors such as nervousness, restlessness, taking of medication or alcohol. If the subjects had taken either analgesic medication or alcohol, no test was performed on that day. When both tests were finished, the word "pain" was mentioned by the examiner for the first time. The subject was asked to define "pain," and to state whether he thought the sharp, jabbing end point seemed like a "pain" sensation.

Also, a certain number of subjects were asked to recall if they winced, and to state why they winced.

The results of these tests were then correlated with other clinical and laboratory findings to determine their possible interrelationship.

Most of the tests were made by the same examiner. To rule out any variation which might be due to the tester, another physician performed the test on 18 of the control subjects and 15 of the patients.

\section{RESULTS}

(A) Lowest level at which stimulus is perceived as painful, and at which patient winces or pulls away

Figure 1 presents the data from our second test for the level at which the stimulus was perceived as painful by each patient. The levels at which control subjects and patients with neurocirculatory asthenia perceived the stimulus as painful are almost identical in the 4 groups.

However, when the means of the levels at which stimuli produce wince reaction are compared, patients with chronic N.C.A. react at the lowest level, acute N.C.A. at the next level, convalescents wince at a higher level and the healthy control subjects wince at the highest levels of all (Figure 2). The differences between the chronic N.C.A. and the control groups are significant statistically (Table II).

In addition to the wince reaction, many of the patients pulled their heads away from the apparatus. This response occurred (Table III) frequently in patients and almost not at all in healthy and convalescent controls. At levels lower than .351 gram cal. per sec. per $\mathrm{cm}^{2}, 3$ per cent of healthy control subjects pulled away, 7 per cent convalescents, 32 per cent acute N.C.A. patients, and 49 per cent chronic N.C.A. patients pulled away. The differences at this stimulus level between the N.C.A. patients and the control subject, both healthy and convalescent, are highly sig-

TABLE I

Summary of data on levels at which stimulus is perceived as painful (perception) and at which wincing occurs (reaction)

Perception-Test II

\begin{tabular}{l|c|c|c|c|c|c}
\hline \hline \multicolumn{1}{c|}{ Subjects } & No. & Range & tMean & $*$ S.D. & $\begin{array}{l}* * \mathrm{C} . \\
\text { of V. }\end{array}$ & $* *$ S.E. \\
\hline $\begin{array}{l}\text { Controls, } \\
\text { healthy }\end{array}$ & 44 & .241 to .356 & .2872 & .024 & 8.2 & .0036 \\
$\begin{array}{l}\text { Controls, } \\
\text { convalescent }\end{array}$ & 17 & .225 to .320 & .2834 & .022 & 7.8 & .0053 \\
$\begin{array}{l}\text { N.C.A., } \\
\text { acutes }\end{array}$ & 30 & .245 to .348 & .2918 & .027 & 9.2 & .0049 \\
$\begin{array}{l}\text { N.C.A., } \\
\text { chronic }\end{array}$ & 62 & .225 to .460 & .2866 & .027 & 9.5 & .0034 \\
\hline
\end{tabular}

Reaction-Test II

\begin{tabular}{l|l|l|l|l|l|l}
\hline $\begin{array}{l}\text { Controls, } \\
\text { healthy }\end{array}$ & 44 & .249 to .447 & .3636 & .054 & 15.0 & .0082 \\
$\begin{array}{l}\text { Controls, } \\
\text { convalescent }\end{array}$ & 17 & .235 to .410 & .3574 & .059 & 17.0 & .0143 \\
$\begin{array}{l}\text { N.C.A., } \\
\text { acute }\end{array}$ & 31 & .234 to .416 & .3261 & .058 & 18.0 & .0104 \\
$\begin{array}{l}\text { N.C.A., } \\
\text { chronic }\end{array}$ & 63 & .225 to .460 & .3140 & .070 & 22.0 & .0090 \\
\hline
\end{tabular}

*S.D. = Standard Deviation.

**C. of V. = Coefficient of Variation.

***S.E. = Standard Error.

†Mean in Gm. cal./sec. and cm. 


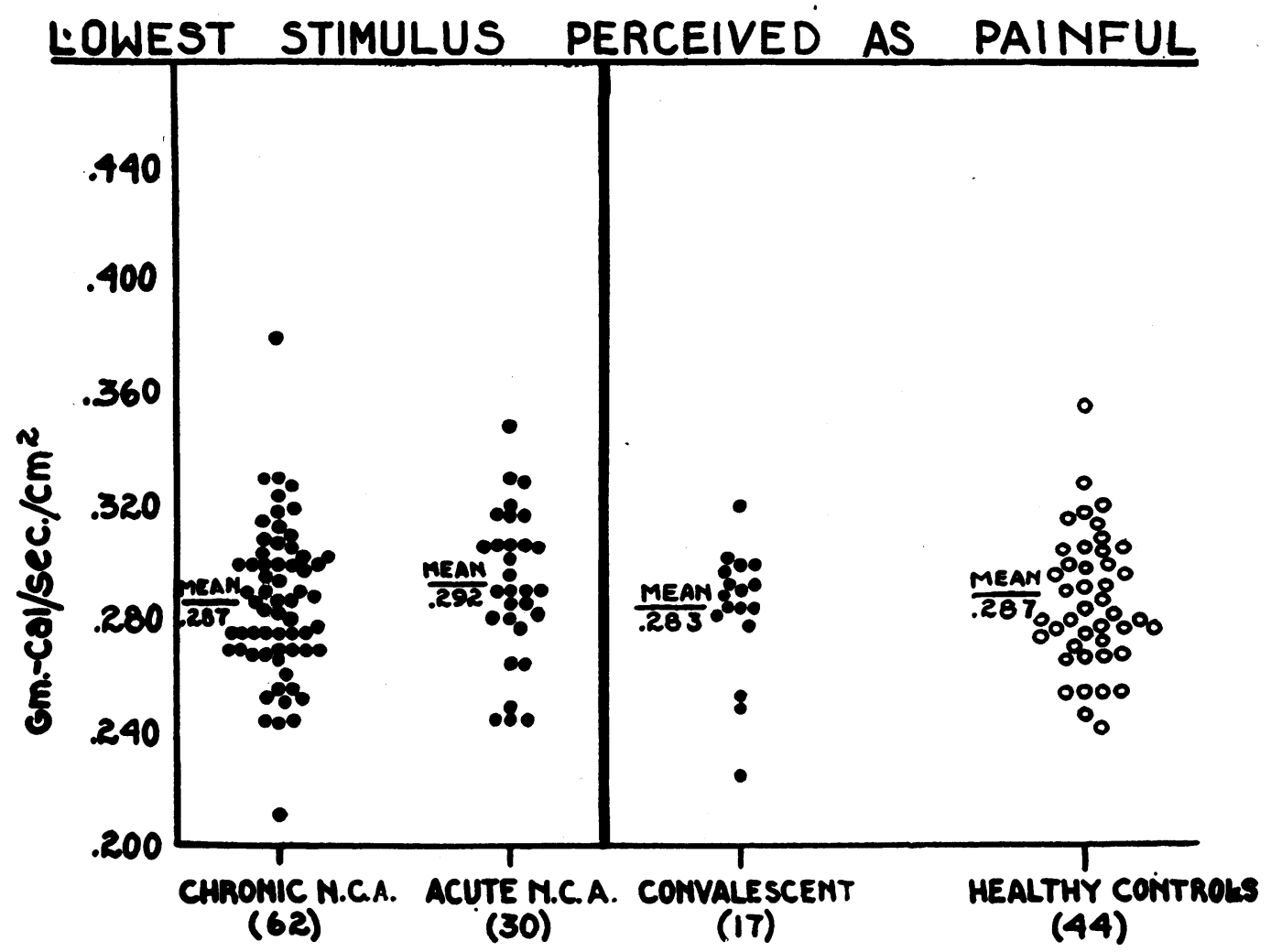

Fig. 1. The Lowest Level of Heat Stimulus Perceived as Painful in Each Individual Subject is Presented Above as a Dot or Circle

The levels are indicated on the ordinate in gram cal. and sec. per $\mathrm{cm}^{2}$. The number and type of subjects are indicated along the abscissa. This figure shows that the mean of the observation is the same for all groups. The slight differences are not significant; the distributions are similar for the 4 groups. Above data are charted from values obtained in test II in each case.

TABLE II

Significance of the difference between the means of the various groups

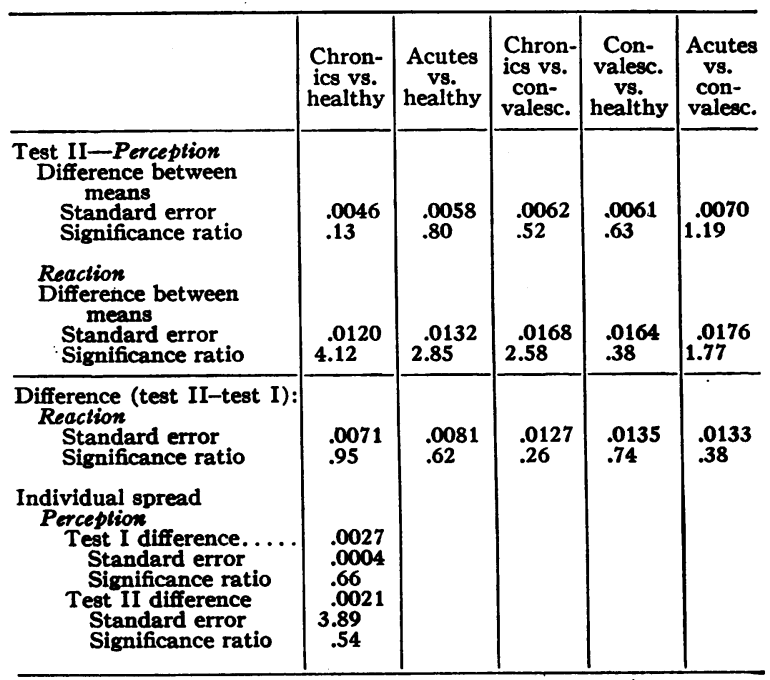

nificant, with a significance ratio of 5.50. Table III also illustrates that at the lowest stimulus level patients and control subjects do not differ particularly, but, as the stimulus is increased, the differences between patients and control subjects in withdrawal becomes more marked. At the 3 highest stimulus levels, a greater proportion of chronic patients pull away from the apparatus than do the

TABLE III

Percentage incidence of pulling head away from apparatus at various heat levels (Controls vs. N.C.A.)

\begin{tabular}{|c|c|c|c|c|}
\hline \multirow{2}{*}{$\begin{array}{l}\text { At level, gram cal. per } \\
\text { sec. and cm.., of less than }\end{array}$} & \multicolumn{4}{|c|}{ Gram cal. per sec. per cm.2 } \\
\hline & .276 & .301 & .326 & .351 \\
\hline $\begin{array}{l}\text { Healthy (28) } \\
\text { Convalescent (15) } \\
\text { Acute N.C.A. (23) } \\
\text { Chronic N.C.A. (50) }\end{array}$ & $\begin{array}{l}0 \\
0 \\
8 \\
5\end{array}$ & $\begin{array}{r}0 \\
0 \\
21 \\
27\end{array}$ & $\begin{array}{r}0 \\
0 \\
30 \\
38\end{array}$ & $\begin{array}{r}3 \\
7 \\
32 \\
49\end{array}$ \\
\hline
\end{tabular}


acute patients. The difference is not, however, statistically significant.

We conclude from the above observations that the level at which the stimulus was perceived as painful is not significantly different from the patient group to the control group. The wince level, however, is lower for the patients than for the controls. The pullaway response occurs more frequently and at a lower stimulus level in the patients than it does in the control subjects.

\section{(B) Consistency of levels of perception and re- action in a given individual during a test}

In an individual case there is a spread between the level at which the patient first perceives the stimulus as painful, and the lowest level at which he consistently perceives the level as painful. This is called the spread in the level of perception. The same phenomenon is also true of reaction, namely, a spread between the level at which the patient first winces, and the lowest level at which the pa- tient winces consistently. The mean levels for test I and II are given in Table IV. The spread of the perception levels does not vary particularly from test I to test II. The means for the spread in the level of reaction are slightly lower in test II than in test I.

\section{(C) Comparison of perception and reaction levels, test I to test II}

The patients and controls were compared as to the variability in results from test I to test II, and also as to the degree of consistency of the endpoints both in perception and reaction during a given test. As shown in Table IV, the results from the second test showed but slight differences from those of the first test.

During the first test, the patients were given no instructions as to the nature of the sensation, but were instructed to look for the sharp, jabbing endpoint during the second test. The results of the 2 tests are almost identical as seen from Table

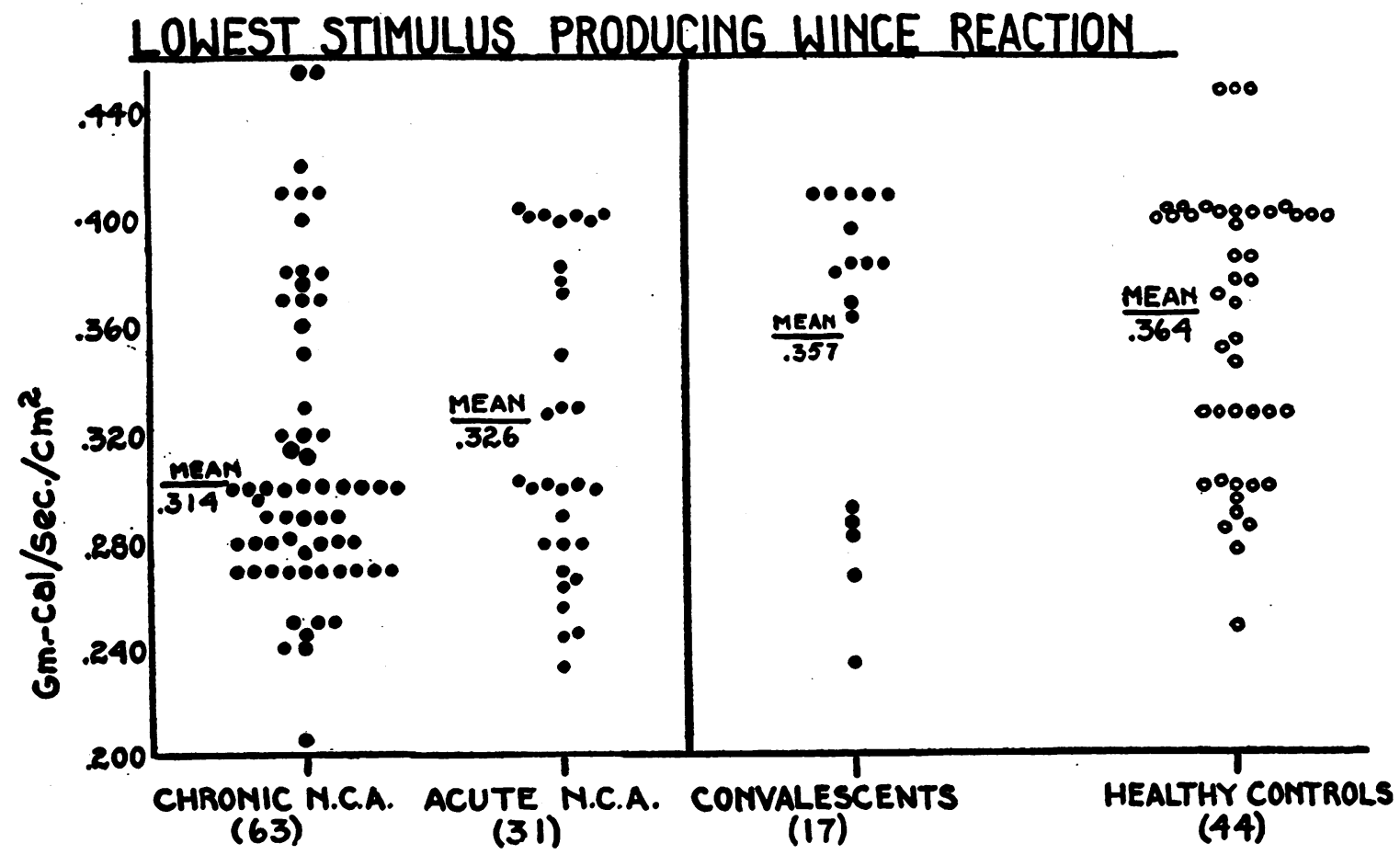

Fig. 2. The Lowest Heat Stimulus Producing Wince Reaction is Represented by a Dot or Circle For EAch SubJect

The levels are indicated on the ordinate in gram cal. per sec. and $\mathrm{cm}^{2}$ The number and type of subjects are indicated along the abscissa. The mean values are significantly lower in both groups of N.C.A. than in healthy control subjects. The group in the chronic N.C.A. differs significantly from the convalescent control group, and from the acute N.C.A. group as well. The above data were obtained from test II in each case. 
TABLE IV-

Test II vs. test I. Comparison of mean results of perception, reaction and consistency

\begin{tabular}{|c|c|c|c|c|c|}
\hline & No. & I & II & $\begin{array}{c}\text { Differ- } \\
\text { ence } \\
\text { (test II- } \\
\text { test I) }\end{array}$ & $\begin{array}{c}\text { Signifi- } \\
\text { cance } \\
\text { ratio }\end{array}$ \\
\hline \multicolumn{6}{|c|}{ Mean perception } \\
\hline $\begin{array}{l}\text { Healthy } \\
\text { Convalescent } \\
\text { Acute } \\
\text { Chronic }\end{array}$ & $\begin{array}{l}31 \\
12 \\
14 \\
36\end{array}$ & $\begin{array}{l}.2845 \\
.2785 \\
.3011 \\
.2840\end{array}$ & $\begin{array}{l}.2821 \\
.2775 \\
.2942 \\
.2861\end{array}$ & $\begin{array}{l}-.0024 \\
-.0010 \\
-.0069 \\
+.0021\end{array}$ & $\begin{array}{r}.70 \\
.26 \\
1.43 \\
.61\end{array}$ \\
\hline \multicolumn{6}{|c|}{ Wince level } \\
\hline $\begin{array}{l}\text { Healthy } \\
\text { Convalescent } \\
\text { Acute } \\
\text { Chronic }\end{array}$ & $\begin{array}{l}29 \\
15 \\
28 \\
57\end{array}$ & $\begin{array}{l}.3343 \\
.3342 \\
.3074 \\
.2899\end{array}$ & $\begin{array}{l}.3404 \\
.3503 \\
.3185 \\
.3027\end{array}$ & $\begin{array}{l}+.0061 \\
+.0161 \\
+.0111 \\
+.0128\end{array}$ & $\begin{array}{l}.55 \\
1.33 \\
2.00 \\
3.26\end{array}$ \\
\hline \multicolumn{6}{|c|}{ Spread in level-perception } \\
\hline $\begin{array}{l}\text { Healthy } \\
\text { Convalescent } \\
\text { Acute } \\
\text { Chronic }\end{array}$ & $\begin{array}{l}31 \\
12 \\
14 \\
36\end{array}$ & $\begin{array}{l}.0126 \\
.0095 \\
.0096 \\
.0153\end{array}$ & $\begin{array}{l}.0129 \\
.0058 \\
.0124 \\
.0150\end{array}$ & $\begin{array}{l}+.0003 \\
-.0037 \\
+.0028 \\
-.0003\end{array}$ & \\
\hline \multicolumn{6}{|c|}{ Spread in level-reaction } \\
\hline $\begin{array}{l}\text { Healthy } \\
\text { Convalescent } \\
\text { Acute } \\
\text { Chronic }\end{array}$ & $\begin{array}{l}44 \\
17 \\
31 \\
63\end{array}$ & $\begin{array}{l}.0200 \\
.0200 \\
.0300 \\
.0230\end{array}$ & $\begin{array}{l}.0100 \\
.0200 \\
.0240 \\
.0120\end{array}$ & $\begin{array}{r}-.0100 \\
.0000 \\
-.0060 \\
-.0110\end{array}$ & \\
\hline
\end{tabular}

IV. None of the differences between these means was great. From this we conclude that the level at which the stimulus is perceived as painful is fairly consistent from test to test in the same individual, and that doing the procedure with either technique yields the same results. Also there was no difference in results depending on the tester.

In contrast, the wince level tends to be slightly higher in the second test than in the first one, that is, the patient stands more stimulus before he winces when tested a second time. This is true of all 4 groups, but only in the N.C.A. patients are the differences from test I to test II statistically significant (Table IV).

\section{(D) Was the perception endpoint really perceived as painful?}

In answer to the question whether the sharp, jabbing endpoint was regarded as painful, the subjects were asked (1) to define pain, (2) whether the sharp jabbing endpoint was "a pain." Both the patients and controls regarded pain as some form of hurting sensation. The sharp jabbing endpoint was regarded as a painful stimulus in all but 3 of 79 subjects. The reason given for calling the pain perception endpoint "painful" was almost always that it had a "hurting" quality.

\section{(E) Description of pain endpoint in N.C.A. as compared with controls}

At the level at which the stimulus was perceived as painful, the patients described the pain in an identical manner as the control subjects, that is, as a sharp jabbing, sharp piercing, sharp pricking of a needle.

\section{(F) Subject's explanation for wincing}

The patient was asked why he winced. Among the common explanations given were "it hurt," "it was a painful sensation," "it helped me withstand the pain." Some also stated that they didn't know or were not aware that they had winced.

\section{(G) Relationship of wince level to other data}

The data in patients were examined to discover if there was any relationship between wince levels and other findings such as the work index, blood lactate levels associated with work, ventilation index, familial incidence of this condition, number of symptoms in the present illness and in the past medical history, and the type of chief complaint. With the exception of chief complaint, there was no obvious relation between the wince levels and any of the above factors, although no planned intensive study of all possibilities was made.

The wince level of 22 patients whose chief complaint was "nervousness" was .301 gram cal. per sec. and $\mathrm{cm} .{ }^{2}$, in contrast to .329 gram cal. per sec. and $\mathrm{cm}^{2}$ in 56 patients with chief complaints other than "nervousness." The difference between the levels is statistically significant (significance ratio 2.08 , odds against this being a chance occurrence, are 25 to 1 ), demonstrating that there is a lower wince level in patients with chief complaints of "nervousness" as compared to those in the other chief complaints such as chest pain, weakness, breathlessness, headache, and dizziness. 
$(H)$ Is there a relation in individual cases between perception and reaction levels?

When individual data for perception and wince levels were correlated in the 4 groups, it was found that in each group the reaction level depended on the level of perception. The higher the perception level the higher was the level of reaction

The values for the correlation coefficients are: chronic N.C.A., .64; acute N.C.A., .29; convalescent controls, .50; healthy controls, .53 , all but the second being significant. Inasmuch as the mean perception level in all 4 groups was the same, the low wince levels in the patient groups could not be explained by a low perception level.

\section{SUM MARY OF RESULTS}

(A) 1. Patients with N.C.A. perceive the heat stimulus as painful at the same level as do the control subjects.

2. Patients with N.C.A. wince at a lower level of stimulus than do the controls.

3. This is also true for the levels at which they pull away from the apparatus, a higher proportion of patients withdrawing at each level and at lower levels as compared with the controls.

4. Patients with chronic N.C.A. react (wince, pull away) at lower levels than do patients with acute N.C.A.

(B) The degree of consistency of the levels at which each stimulus is perceived as painful, and at which wincing occurs, was no different in patients and controls during a given test.

(C) 1. Perception levels do not differ significantly from test I to test II.

2. Wince levels tend to be slightly higher in test II ; this is significantly so in both groups of N.C.A. patients.

3. Similar results were obtained in perception level, whether subject is instructed to look for jabbing sensation or is given no instruction and volunteers a description of this endpoint.

4. There is no change in consistency in pain or wince level from test I to test II.

$(D)$ The subjects report the stimulus as a jabbing, piercing, hurting sensation and agree that it is painful.

(E) Patients and control subjects use the same type and intensity of wording in describing the heat stimulus at the pain perception endpoint.
$(F)$ Patients explained that they winced because "it hurt" or to "withstand the pain."

$(G)$ There was a significantly lower wince level in patients with chief complaint of nervousness than in patients with the chief complaints other than nervousness, such as chest pain, headache, weakness, breathlessness, or dizziness. There was no other correlation of wince level with other findings from history, or from other tests.

$(H)$ There is positive correlation in individual cases between levels of perception and reaction (wince).

\section{DISCUSSION}

This test measures the amount of heat stimulus which is perceived as painful on the mid-line of the forehead. The fact that this is the same for patients and controls does not imply that the same would hold for other locations, for visceral pain, or for other unpleasant stimuli. No support is offered by this finding for the idea that these patients complain more of discomfort because they feel pain with less stimulus. The patients' description makes it certain that it is a pain that is experienced and not some other sensation, as far as one can be certain of sensation.

The reaction level offered an estimation of the amount of stimulus at which motor reaction occurred.

The exact neurologic pathways of these responses are not known, nor is the entire significance of them understood. The fact that the patients with "nervousness" as a chief complaint show the lowest wince levels, suggests that the factor of "nervousness" may be an important factor in the low wince levels in N.C.A. In other studies, low wince level has been shown to be related to age and ethnic group of subject (3), but these factors are not important in this study, as comparable controls were used.

The finding of a low wince level in N.C.A. corresponds with a similar finding in a previous study (4) in various types of neurosis. This provides a further point of correspondence between neurocirculatory asthenia and patients commonly placed in the neurosis category (5). In this paper neurocirculatory asthenia, anxiety neurosis, and effort syndrome are considered as synonyms describing one syndrome (6).

The patients' reaction at a lower stimulus level 
corresponds to the patients' poor performance in holding an uncomfortable grip dynamometer, poor performance in breath holding, and in general to patients' statement of inability to tolerate discomfort (1).

It is of further interest that the values check from test I to test II and during each test, despite the subjective nature of part of the procedure. The checks are as good in the patients as in controls, suggesting that patients of this type may be consistent witnesses of subjective data.

This test might be used as an aid in the diagnosis of neurocirculatory asthenia, effort syndrome, and anxiety neurosis. A wince level above .400 gram cal. per sec. and $\mathrm{cm}^{2}$ makes a diagnosis of neurocirculatory asthenia improbable, as fewer than 10 per cent of patients are above .400 . A wince level below .290 gram cal. per sec. and $\mathrm{cm}^{2}$ is corroboration for the diagnosis of neurocirculatory asthenia, it being improbable that such a subject is normal, as only 10 per cent of healthy controls fall below this level.

\section{CONCLUSIONS}

1. The level at which patients with neurocirculatory asthenia, effort syndrome or anxiefy neurosis perceive the heat stimulus as painful is the same as that for control subjects.

2. In contrast, the level at which the N.C.A. patient reacts to the heat stimulus (winces, pulls away) is lower than that for the control subjects.

3. This difference is most marked in chronic N.C.A. ; less in acute N.C.A.
4. N.C.A. patients with nervousness as a chief complaint wince at a lower wince level than do N.C.A. patients with other chief complaints.

5. The reaction of N.C.A. patients at a low stimulus level offers a quantitative correlate of the clinical impression of the patients' inability to stand discomfort.

6. This test may be of use in establishing the diagnosis of neurocirculatory asthenia, effort syndrome, or anxiety neurosis.

\section{BIBLIOGRAPHY}

1. Cohen, M. E., Johnson, R. E., Cobb, S., Chapman, W. P., and White, P. D., Studies of work and discomfort in patients with neurocirculatory asthenia. J. Clin. Invest., 1944, 23, 934.

2. Hardy, J. D., Wolff, H. G., and Goodell, H., Studies on pain. A new method for measuring pain threshold: Observations on spatial summation of pain. J. Clin. Invest., 1940, 19, 649.

3. Chapman, W. P., and Jones, C. M., Variations in cutaneous and visceral pain sensitivity in normal subjects. J. Clin. Invest., 1944, 23, 81.

4. Chapman, W. P., Measurement of pain sensitivity in normal control subjects and in psychoneurotic patients. Psychosom. Med., 1944, 6, 252.

5. White, P. D., Cobb, S., Chapman, W. P., Cohen, M. E., and Badal, D. W., Observations on neurocirculatory asthenia. Trans. Ass. Am. Phys., 1944, 58, 129.

6. Cohen, M. E., Johnson, R. E., Chapman, W. P., Badal, D. W., Cobb, S., and White, P. D., A study of neurocirculatory asthenia, anxiety neurosis, or effort syndrome. Final report to the Committee on Medical Research of the Office of Scientific Research and Development under Contract OEMCMR-157, 135 pp., 1946. 